\title{
Low noise moving target detection in high resolution radar using binary codes
}

Majid Alotaibi

\author{
Correspondence: mmgethami@uqu. \\ edu.sa \\ Department of Computer \\ Engineering, College of Computer \\ and Information Systems, Umm \\ Al-Qura University, Makkah, Saudi \\ Arabia
}

\begin{abstract}
Radar technology plays a vital role in enhancing surveillance of the battlefields and physical borders, disease detection, and weather prediction. However, there exist certain challenges like detecting fast-moving targets. When targets are moving at a significantly high speed, it is not easy to detect them compared to static and slowmoving targets, which are easily detected. In this regard, the research community has, over the years, tried to improve radar technology to detect fast moving targets in presence of Doppler noise. In this paper, various binary codes have been proposed to minimize the noise peaks below the radar threshold limit to create multiple windows that enable precise information of the moving targets. These sequences also have good autocorrelation attributes to get a higher range resolution and compression ratio. Validation of the proposed method is performed using Matlab simulations. Results show that the noise amplitudes are reduced to $0.2 \mathrm{~dB}$ well below the prescribed threshold.
\end{abstract}

Keywords: Signal-to-noise ratio, Side lobes, Ambiguity, Autocorrelation, Matlab

\section{Springer Open}

\section{Introduction}

Radars are a well-known object recognition system that consists of transceiver which initially transmits signals, and then, the received echo signals are used to calculate speed, distance, angle, shape, and size of objects. Radar technology finds its use extensively in medicine for identifying diseases, by militaries to track adversarial positions with respect to time, and various civil applications like approximate recognition of vehicles, sea observation, climate prediction, and to obtain certain the geological parameters. To accomplish the required objective of target discovery, continuous waveform (CW) radar is mainly employed to find the location of the object, as it incessantly sends the signals via transmitting end to notice the object, and the signals reflected from the object (echoes) are acknowledged at the recipient end. The key benefit of this radar is to measure its specific Doppler effect. However, due to continuous transmission of signals, it produces uncertainty in the target scope and necessitates dual aerials. To reduce the uncertainty and dual antenna system, pulse radar is utilized in contemporary systems as it gives the exact range statistics, and a single aerial is used for both transmission and reception. The aerial behaves as a transmitter in the duration of the

(c) The Author(s). 2021, corrected publication 2021. Open Access This article is licensed under a Creative Commons Attribution 4.0 International License, which permits use, sharing, adaptation, distribution and reproduction in any medium or format, as long as you give appropriate credit to the original author(s) and the source, provide a link to the Creative Commons licence, and indicate if changes were made. The images or other third party material in this article are included in the article's Creative Commons licence, unless indicated otherwise in a credit line to the material. If material is not included in the article's Creative Commons licence and your intended use is not permitted by statutory regulation or exceeds the permitted use, you will need to obtain permission directly from the copyright holder. To view a copy of this licence, visit http://creativecommons.org/licenses/by/4.0/. 
pulse time $P_{d t}$, and it behaves as a receiver in duration of pulse time $P_{r t}$. Pulse compression techniques have been traditionally employed to process signals in a radar system. These techniques use long pulses at the transmitter side to improve the scope of target detection and short duration pulses to acquire a high resolution at the recipient side. In multiple-object environment, it is difficult to detect a single object which is of a smaller size. Resolution plays a vital role to discriminate the required target in a multipleobject environment. In art of work, pulse compression-matched filtering approach is used to find the current position of the target using autocorrelation property. This approach optimizes the amplitude of side lobes which can hide the desired targets. To achieve the side noise suppression noise, several codes such as Barker, Golay, PTM, and other optimized techniques have been tested. Nevertheless, all these methods fail to detect the multiple and moving target. In [1,2], the authors optimized the target detection using feedback and cognitive approaches. However, in both the approaches, delay is increased which reduces the probability of multiple moving target detection. Levanon [3] proposed an inter pulse coding technique to enhance the target detection, but the approach is limited to low- and mid-range targets. Shi et al. [4] compares a pseudo-random binary phase coding and the chirp modulation to estimate the performance of target detection.

In this paper, several digital codes have been proposed with good autocorrelation function and Doppler tolerance. These codes are used to detect the object which is static or moving in multi-object ambience. The side noise in autocorrelation is optimized, and side noise in the ambiguity plot is almost approximated to the threshold of $0.2 \mathrm{~dB}$. The validation of designed codes is done using Matlab. In this article, we propose the following:

i. A method to optimize the side noise in autocorrelation function plot and improve the Doppler tolerance of the codes obtained.

ii. Linear block code $(7,4)$ is used to obtain the binary sequence code of the lengths 128 and 256 (by performing some mathematical operations on $(7,4)$ codes).

\section{Related work}

Tian et al. [5] designed poly-phase radar codes with a lower signal-to-noise ratio (SNR) by making use of the Wigner-Ville distribution (WVD). But the noise lobes were still significant, and this method is suitable for electronic intelligent systems only. Kretschmer and Lewis [6] discussed the Doppler effect of the combined poly-phase sequences p1, p2, p3, and p4, and the frank codes. A comparative analysis is represented in which there was $4 \mathrm{~dB}$ loss of the signal in a cyclic manner, and the loss increased when phase shift was an odd multiple of $\pi$ across the non-compressed pulses. However, when the Doppler frequency is increased, p3 and p4 may fail to produce accurate results in case of moving targets. Sivaswami [7] presented the repetitive Hadamard sequence which is sub-complemented codes; the ambiguity functions of these codes are combined to neutralize the effects of self-clutter. But this method increases hardware complexity as the numbers of filters are high which are required to produce the combined effect of their outputs with significant noise induced. Guey and Bell [8] presented a method to obtain the measurements of the ambiguity function by using multiple signals. These signals may be phase or frequency coded or combination of both phase and frequency 
with constant signal amplitude. However, this approach requires several radars to monitor a single target which increases the hardware complexity and constraints its application. The author in [9] designed the matrix of complementary sequences in which the columns of the matrix forms the code vector. The codes used to form this matrix are binary uni-modular complementary codes of the same length such that the autocorrelation of the side lobes sums to " 0 ". But the complexity increases, and it is a timeconsuming process. Chang and Bell [10] proposed different techniques to develop sequences based on the frequency where the side lobes are minimum, and clear windows are formed to detect the target which is masked. The codes were termed as a pushing sequence. However, side lobe increases as the perfect error-correcting codes using lee code words increases. Deng [11] proposed a hybrid algorithm for optimization which is used to design polyphase codes. The hybrid algorithm used combines the method of annealing and iterative selection of codes. But the iterative codes consume more time when the code length is increased. And as the netted radar systems are used with an increase in the code length, the hardware complexity also increases. When the delay increases, the precise detection of the moving target is rarely possible.

Pezeshki et al. [12] used Golay complementary codes to be sequenced in pulse amplitude modulation to mitigate the range side noise in the desired interval of Doppler, and using the orthogonal frequency multiplexing, the Doppler side noise in the desired interval range is root out. However, this method requires a library of phase codes with pairs of complementary codes which is practically difficult. Deng [13] designed the binary sequence with good cross and autocorrelation function by using an optimization algorithm known as annealing simulation to reduce the side noise this algorithm converges globally and is robust. However, the algorithm presented is not used to its full potential as it consumes more CPU time. Gladkova and Chebanov [14] discussed the suppression of the undesirable side peaks produced at the matched filter output when the input of uniform frequency stepped pulse train is provided. This method is not capable of detecting the moving targets. Levanon and Mozeson [15] discussed the suppression of grating lobes of autocorrelation function using linear frequency-modulated pulses to obtain better resolution of range. However, to make the significant suppression, the step size of normalized frequency should be small, and the pulses should be high in number. Jenshak and Stiles [16] presented a method of obtaining the sequence with low-error estimation of the range which in turn lowers the side lobes. These codes detect only the static objects. The authors of $[17,18]$ presented two different techniques to improve the Doppler tolerance of moving targets. However, both the techniques maximize the mathematical complexity and delay which reduces the efficiency of target detection and may not be optimum to detect fast-moving targets. Raghavendra et al. [19] proposed a novel approach to reduce the power and side lobe in multi-carrier radar. However, the authors fail to improve the autocorrelation function which cannot detect the target precisely. Adithya et al. [20] proposed convolution window technique to reduce side lobes. However, this method cannot be used to detect moving targets, as the amplitude of side lobes are more than the threshold limit, i.e., $0.2 \mathrm{~dB}$.

\section{Background and motivation}

The pulse compression techniques can be classified as frequency modulation and phase modulation. Frequency modulation is further classified as frequency hopping and linear 
and non-linear pulse compression method. In linear frequency pulse compression technique, the linear frequency-modulated signal is used as a transmitting signal. This technique is simple, but jamming of the signal is incorporated with it. Non-linear frequency pulse compression technique and the non-linear frequency-modulated signal are used as a transmitting signal. It requires no amplitude weighing of the signal but has system complexities.

In phase modulation, the pulse compression technique is a digital method in which the pulse with long duration $\left(t_{\mathrm{r}}\right)$ is subdivided into short-duration pulses $\left(t_{\mathrm{s}}\right)$. The pulse compression ratio is given as $t_{r} / t_{s}$. Bi-phase or polyphase codes can be used in this technique. In bi-phase coding, the phases chosen are 0 or $180^{\circ}$, and in the polyphase code sequence, the phase can be varied from 0 to $360^{\circ}$. However, the poly-phase sequences are susceptible to the Doppler shift.

3.0.0.1 Ambiguity function It is the perfect value of the enclosure at the match filter output when the input signal to the filter is Doppler shifted to that of the signal which was matched by the filter. It can also be defined as the match filter time response for the energy signal, which is finite and is Doppler shifted and delayed when compared to the desired zero value of the filter at the receiver. It is a 3D figure of the amplitude variation in accordance with the Doppler and delay. The major properties of the ambiguity function are as follows:

- The ambiguity function has its maximum amplitude at the origin

- The graph exhibits symmetric property to the origin

- The regular volume of the graph irrespective of different waveforms

In this paper, binary phase-coded pulse compression sequences are used as it is a digital technique, unlike the frequency modulation pulse compression which is an ana$\log$ method. The performance of the radar system can be measured by two parameters represented as

- Peak to side-lobe ratio $\left(P_{\text {SLR }}\right)$

$$
P_{S L R}=10 \log _{10} \frac{\text { Power of side-lobe peaks }}{\text { Power of main-lobe }}
$$

Integrated peak to side-lobe ratio $\left(I_{\mathrm{SLR}}\right)$

$$
I_{\mathrm{SLR}}=10 \log _{10} \frac{\text { Power of side-lobe peaks }}{\text { Power of main-lobe }}
$$

The well-known phase code pulse compression is Barker sequences, pseudorandom sequences, Golay sequences, and PTM sequences. These sequences are being commonly used for side lobe reduction.

\subsection{Barker sequences}

Barker code or sequences are the sequence of finite binary digits consisting of -1 and +1 . The only available lengths of barker sequences are $2,3,4,5,7,11$, and 13 with the 
$P_{\text {SLR }}$ of $-6 \mathrm{~dB}$ for the sequence length of 2 and $-22 \mathrm{~dB}$ for the sequence length of 13 . The autocorrelation output of these sequences gives the side lobes with the magnitude of unity, i.e., 1 as presented in Fig. 1. Unfortunately, there are no Barker sequences of more than length 13, which is not suitable in many applications when a higher compression ratio is required. To maximize the pulse compression ratio, the codes with greater length are required in many applications. Therefore, the main disadvantage of the Barker sequence is the limited length of the codes.

To overcome this issue, compound Barker codes were designed by combining two Barker codes by employing the product of Kronecker. If one code is of length " $a_{1}$ " and the second code is of length " $a_{2}$ ", then the compound Barker code obtained from these two codes is of the length of " $a_{1} a_{2}$ ". By increasing the length of the code, the pulse compression ratio was improvised, but the side lobes obtained at the output of the matched filter have larger amplitude, unlike the original Barker codes which gave unity amplitude of the side lobes.

The ambiguity function of barker sequence has normalized noise amplitude more than 0.5 (see Fig. 2) and is distributed over a wide range of Doppler frequencies. This shadow of one target can mask the other targets present in the background and remain undetectable when Barker code is employed.

\subsection{Pseudorandom sequences}

These codes are obtained using modulo- 2 adder, shift registers, and a feedback loop. There are $2^{\mathrm{m}}$ possible states if the shift register is of $\mathrm{m}$-stage. The maximum sequence length will be of $2^{\mathrm{m}}-1$ period. There is a wide scope of obtaining the codes with minimum side lobes. However, it consumes a lot of time in figuring out the sequence with good autocorrelation and minimum amplitude of side lobes as it is a trial-and-error method. These codes are generated randomly without any specific method or technique.

\subsection{Golay sequences}

Golay code was introduced by Golay [21] to deal with the spectrometry. It is a binary sequence generally used as error-correcting codes in communication systems. These

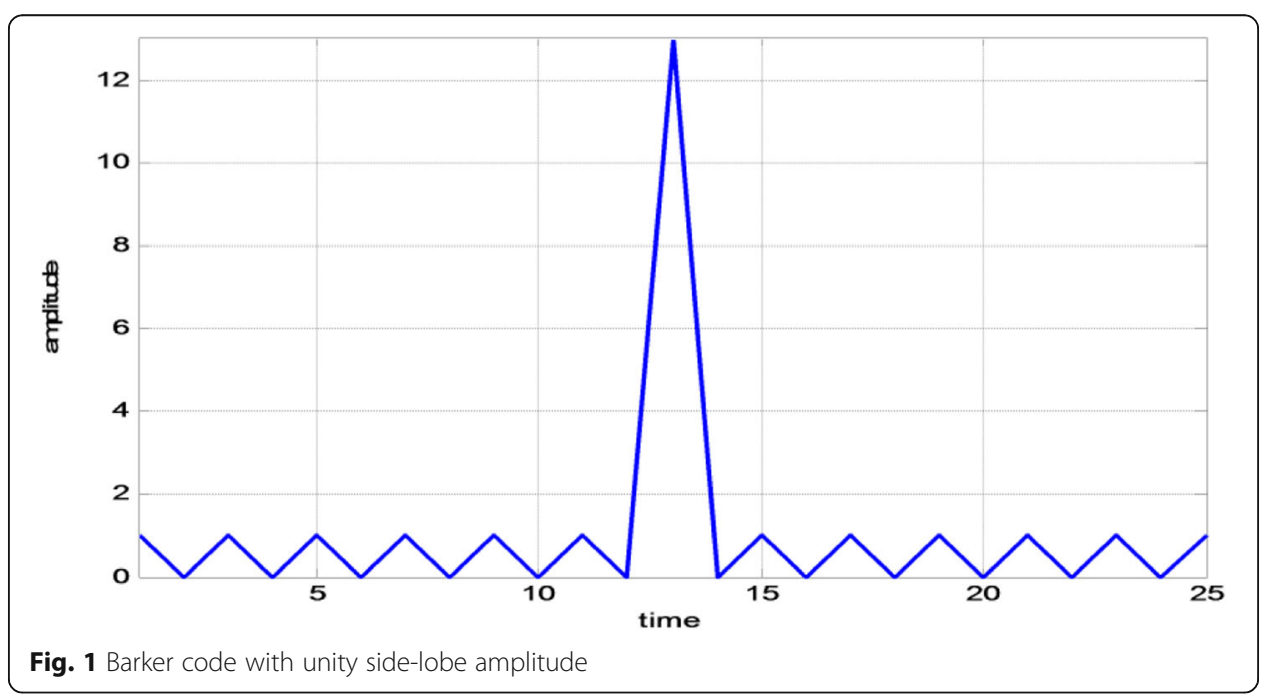




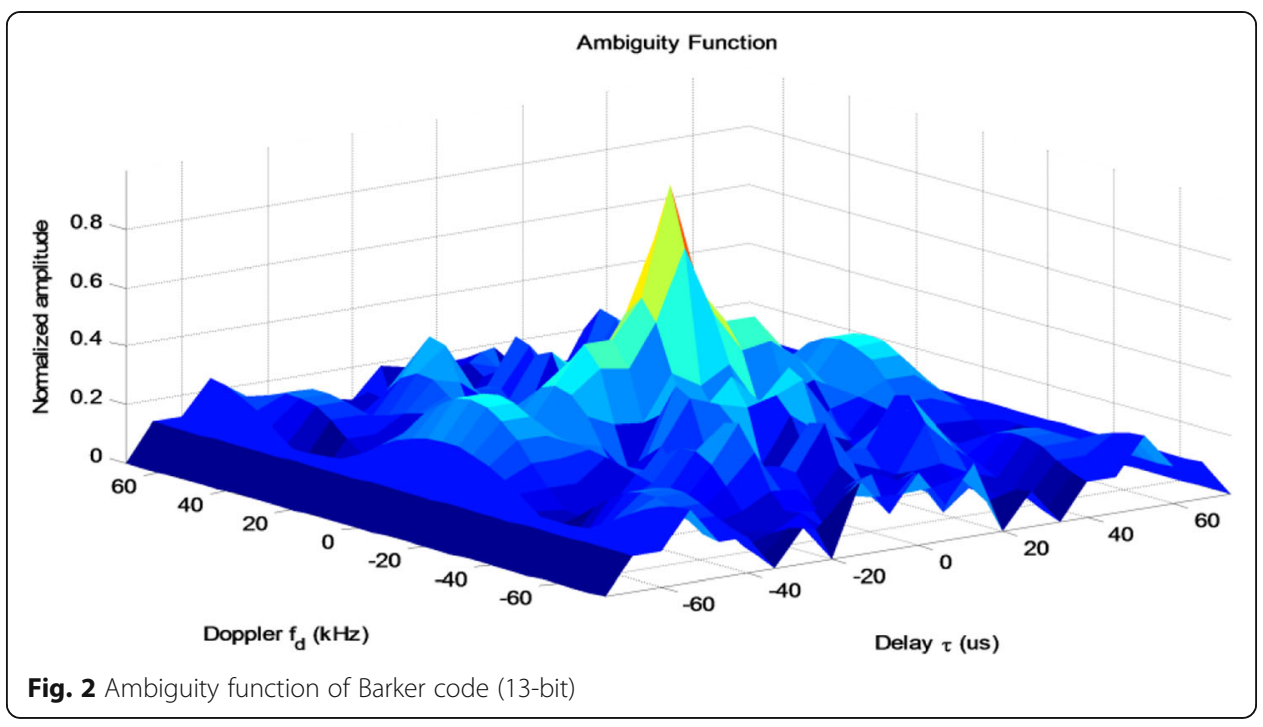

codes give zero side lobes as the result of two complementary codes which are added. These two complementary codes were transmitted in a different cycle of pulses, and at the receiver end, they were correlated. When a complementary pair of code is employed, the match filter output of the coefficients which are out of phase and nonperiodic sums to " 0 ". Hence, the side lobes are mitigated at the match filter output. A modified Golay code was also designed to obtain better results at the output of the filter. But these codes were able to detect the targets in a static environment. In the multi-target environment, these codes increase the side lobes of the autocorrelation and degrade the performance of the system.

\subsection{Prouhet-Thue-Morse (PTM) sequences}

These codes can be obtained by concatenation of the digit and its complement, and the initial bit can be either " 0 " or " 1 ". For example, if we consider "1" as the initial bit, then, 2-bit length PTM code will be "1" concatenated with its complement "0", i.e., "10".

On further complementing, the 4-bit length code obtained is "1001", the 8-bit code will be 10010110, and so on. Figure 3 presents the autocorrelation of 16-bit PTM sequence. All the codes generated are of length $2^{x}$ where $x=0,1,2,3,4 \ldots .$. , and there is no restriction in the length of the code, one can easily generate the sequence to the desired length, unlike the barker and Golay sequence.

The ambiguity function of PTM sequence is less distributed than that of barker code with same normalized noise amplitude of $0.5 \mathrm{~dB}$ (see Fig. 4). It creates only one window (i.e., $10-25 \mathrm{kHz}$, which is very close to $0.2 \mathrm{~dB}$ ) that will be helpful to detect the masked targets up to certain Doppler. However, other than these two windows, the noise amplitude remains larger which will affect the system performance.

In this paper, different binary code sequences have been proposed which not only improve the autocorrelation but also enhance the target detection in the presence of Doppler. Different codes with various lengths are generated to reduce the side lobes to the desired level of autocorrelation and obtain clear windows to detect the target which is masked in the shadow of slow-moving targets. 


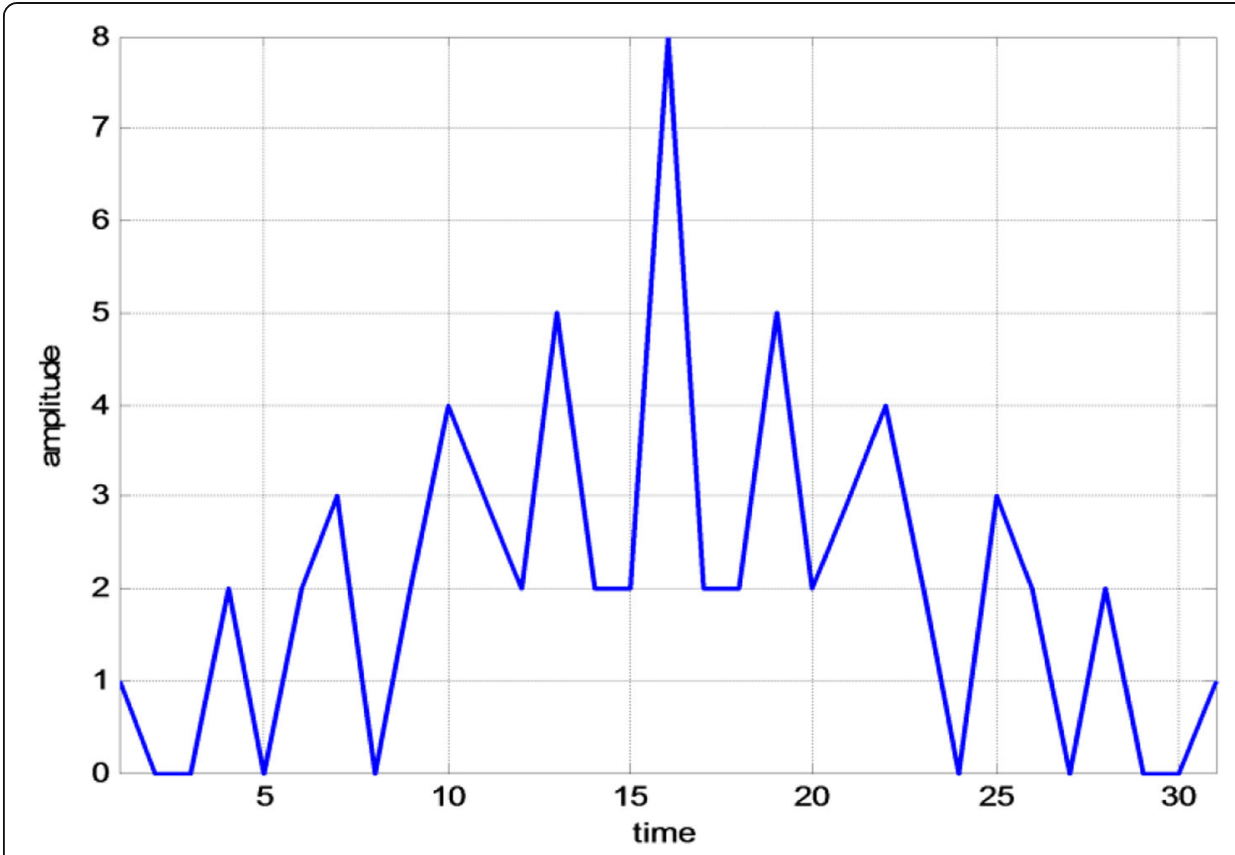

Fig. 3 Autocorrelation of 16-bit PTM sequence

\subsection{Gold and Kasami sequences}

A Gold sequence is a binary code used for target detection in a radar system. This sequence has $2^{z}+1$ code with $2^{z}-1$ period each. " $z$ " is the shift register with linear feedback used to obtain maximum sequence of length 67 . The autocorrelation of the 16-bit length Gold codes obtained in [22] is of noise side lobe of amplitude 18. In Kasami

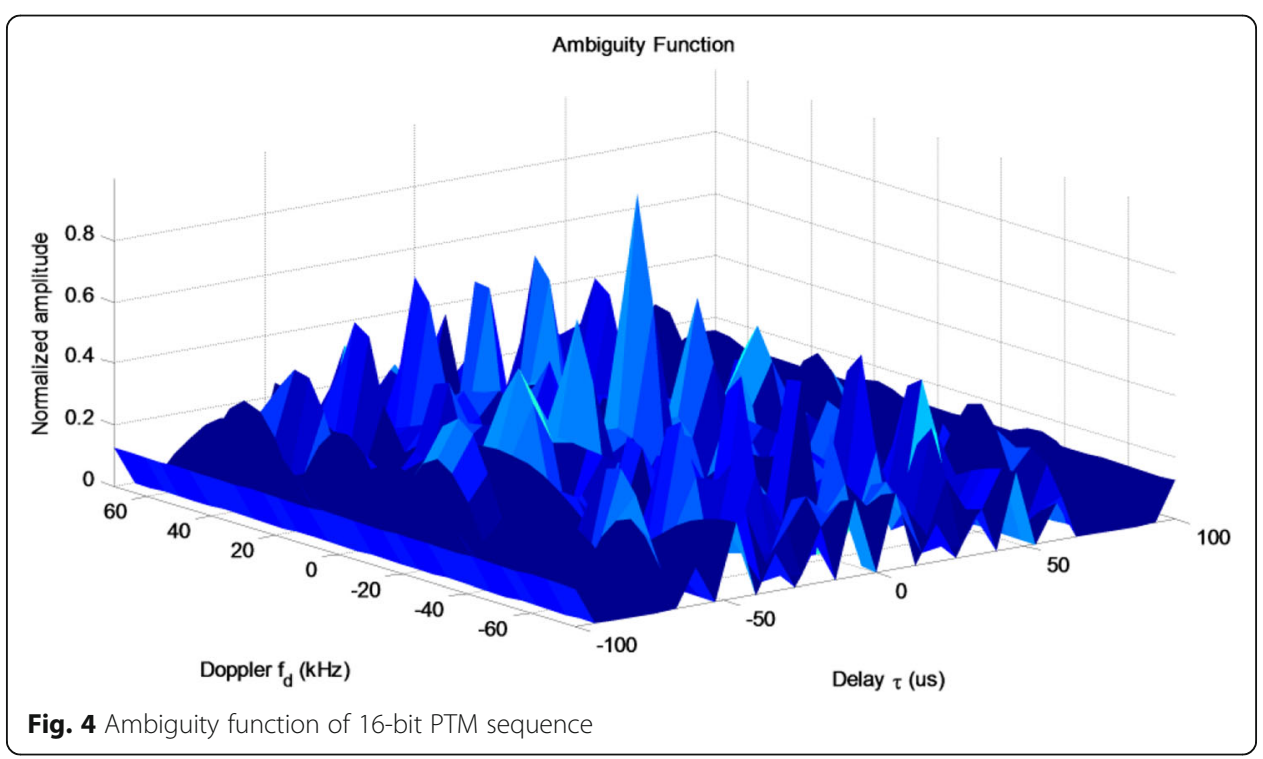


sequence, the sequence with maximum length is $I(g)$ where $g=1, \ldots .2^{G}-1$. The sequences with maximum length are periodic with the period of $2^{G}-1$. The Kasami code of length 64-bit in [23] has the autocorrelation side lobe value as 15 .

\section{Proposed approach}

Table 1 presents the abbreviations and their description used in this paper. In this section, digital binary codes are generated using linear block codes $(\operatorname{LBC}(7,4))$ used to generate the series of digital codes that are tested in this paper in which optimal results are obtained when compared to the standard codes. LBC reduces the mathematical calculation and hardware as these codes are already being used in communication systems which in-turn reduces the delay. Reduction in delay enhances the target detection in multi-object ambience by creating clear windows in presence of noise.

\subsection{Generation of $(7,4)$ code}

To generate 7-bit digital code, 4-bit input binary code $I_{C j}$ is required where $j=2^{4}$ (i.e., $j$ $=0,1, \ldots, 15$ in decimal and 0000, 0001, 0010, ... 1111 in binary number system respectively). These input codes are multiplied to the generator matrix using mod 2 additions. The generator matrix $G_{M}$ is represented as

$$
G_{M}=\left(\begin{array}{l}
1000111 \\
0100110 \\
0010101 \\
0001011
\end{array}\right)
$$

For linear block codes, the generator matrix is pre-defined. The dimensions of this matrix depend on the length of the linear block code $(m, n)$ (here $(m, n)=(7,4))$.

The final 7-bit code $F_{C j}$ can be represented as

$$
F_{C j}=I_{C j} \times G_{M}
$$

For example, when $j=0$

$I_{C 0}=0000$ then

$$
F_{C O}=I_{C O} \times G_{M}
$$

Table 1 Abbreviations

\begin{tabular}{ll}
\hline Symbols & Description \\
\hline$P_{\mathrm{dt}}$ & Transmitter pulse duration \\
$P_{\mathrm{rt}}$ & Receiver pulse duration \\
$t_{\mathrm{r}}$ & Pulse with long duration \\
$t_{\mathrm{s}}$ & Pulse with short duration \\
$P_{\mathrm{SLR}}$ & Peak side-lobe ratio \\
$I_{S L R}$ & Integrated peak side-lobe ratio \\
SNR & Signal to noise ratio \\
$\mathrm{Rr}$ & Side noise reduction ratio \\
\hline
\end{tabular}




$$
\rightarrow[0000] \times=\left(\begin{array}{c}
1000111 \\
0100110 \\
0010101 \\
0001011
\end{array}\right)
$$

$$
F_{C O}=0000000
$$

when $j=1, I_{C 1}=0001$ then

$$
\begin{aligned}
& F_{C 1}=[0001] \times\left(\begin{array}{c}
1000111 \\
0100110 \\
0010101 \\
0001011
\end{array}\right) \\
& F_{C 1}=0001011
\end{aligned}
$$

In similar manner, the rest of the codes are obtained and are presented in Table 2.

The proposed technique follows an algorithm to obtain Doppler tolerant and improved autocorrelation property with the help of $(7,4)$ codes generated and can be represented as.

Step 1: Append even or odd parity bit to the 7-bit code $F_{C j}$ to make it a standard code (see Table 3).

Step 2: Residue of 7 is used to get the good results as it follows the orthogonality property and covers maximum changes (as it is an odd number and is close to the given 8 bit code). The residue bits can be changed as per the following rule to get the good autocorrelation and optimum value of the side noise.

\begin{tabular}{|c|c|}
\hline$I_{C j}$ & $F_{C j}=I_{C j} \times G_{M}$ \\
\hline$I_{\mathrm{CO}}=0000$ & $F_{C O}=00000000$ \\
\hline$I_{C 1}=00001$ & $F_{C 1}=0001011$ \\
\hline$I_{C 2}=0 \begin{array}{llll}0 & 0 & 1 & 0\end{array}$ & $F_{C 2}=000100101$ \\
\hline$I_{C 3}=0011$ & $F_{C 3}=000111110$ \\
\hline$I_{\mathbf{C} 4}=0100$ & $F_{C 4}=0100110$ \\
\hline$I_{C 5}=0101$ & $F_{C 5}=0101101$ \\
\hline$I_{\mathrm{C} 6}=0110$ & $F_{C 6}=011100011$ \\
\hline$I_{C 7}=0111$ & $F_{C 7}=0111000$ \\
\hline$I_{\mathbf{C B}}=1000$ & $F_{C 8}=10000111$ \\
\hline$I_{\mathbf{C g}}=1001$ & $F_{C 9}=1001100$ \\
\hline$I_{C 10}=1010$ & $F_{C 10}=1010010$ \\
\hline$I_{C 11}=1011$ & $F_{C 11}=1011001$ \\
\hline$I_{C 12}=1100$ & $F_{C 12}=11000001$ \\
\hline$I_{C 13}=1101$ & $F_{C 13}=1101010$ \\
\hline$I_{C 14}=1110$ & $F_{C 14}=1110100$ \\
\hline$I_{C 15}=1111$ & $F_{C 15}=1111111$ \\
\hline
\end{tabular}

Only 1's are complemented, and no change is made to 0's of the code at residue positions (i.e., 1-, 2-, and 4-bit positions)

Table 2 Generated codes 
Table 3 Generated codes with odd parity

\begin{tabular}{|c|c|c|}
\hline$F_{C j}$ codes & Odd parity bit & $F_{O C j}$ codes \\
\hline$F_{C 0}=000000000$ & 1 & $F_{O C O}=\begin{array}{lllllllll}0 & 0 & 0 & 0 & 0 & 0 & 0 & 1\end{array}$ \\
\hline$F_{C 1}=0001011$ & 0 & $F_{O C 1}=00010110$ \\
\hline$F_{C 2}=0010101$ & 0 & $F_{O C 2}=00101010$ \\
\hline$F_{C 3}=0011110$ & 1 & $F_{O C 3}=00111101$ \\
\hline$F_{C_{4}}=010010110$ & 0 & $F_{O C 4}=01001100$ \\
\hline$F_{C 5}=0101101$ & 1 & $F_{O C 5}=01011011$ \\
\hline$F_{C 6}=0110011$ & 1 & $F_{O C 6}=011100111$ \\
\hline$F_{C 7}=0111000$ & 0 & $F_{O C 7}=01110000$ \\
\hline$F_{C 8}=100001111$ & 1 & $F_{O C 8}=10001111$ \\
\hline$F_{C \boldsymbol{C}}=1001100$ & 0 & $F_{O C 9}=10011000$ \\
\hline$F_{C 10}=1010010$ & 0 & $F_{O C 10}=10100100$ \\
\hline$F_{C 11}=1011001$ & 1 & $F_{O C 11}=101110011$ \\
\hline$F_{C 12}=1100001$ & 0 & $F_{O C 12}=11000010$ \\
\hline$F_{C 13}=1101010$ & 1 & $F_{O C 13}=11010101$ \\
\hline$F_{C 14}=1110100$ & 1 & $F_{O C 14}=11101001$ \\
\hline $\boldsymbol{F}_{\mathbf{C 1 5}}=1111111$ & 0 & $F_{O C 15}=11111110$ \\
\hline
\end{tabular}

Only 0's are complemented, and no change is made to 1's of the code at residue positions

Both 1's and 0's are complemented of the code at residue positions

The quadratic residue is defined as, if there is an integer " $0<x<p$ ", such that

$$
\times^{2}=q(\operatorname{modp})
$$

Then, " $q$ " is said to be a quadratic residue $(\bmod p)$

Step 3: The resultant codes are concatenated to generate the digital codes with the lengths of 128 and 256 (as the recent research considers the codes of these lengths). Step 4: Auto-correlation property of the obtained codes is tested.

The 0's in the code are replaced with - 1's so as to get the amplitude value equal to the length of the code.

Step 5: Doppler tolerance of the codes are tested; in this test, no changes are made to the codes obtained.

In the proposed approach, odd parity (step 1 ) is appended to the $F_{C j}$ codes, and the resultant codes $F_{O C j}$ are presented in Table 3.

Now considering step 2, Tables 4 and 5 depict all the three cases of this step.

To improve the signal-to-noise ratio (SNR) and autocorrelation property of the received echo signal, the length of the linear block code is increased. Here, digital codes of lengths 128 and 256 bits are designed and tested. 
Table 4 Generation of codes $\left(P_{j}\right)$ as per step 2, case 1

\begin{tabular}{|c|c|c|c|c|c|c|c|c|c|}
\hline \multirow[t]{2}{*}{$F_{O C j}$ codes } & \multicolumn{9}{|c|}{ Only 1's are complemented at residue positions ( $\mathrm{P} 1, \mathrm{P} 2$, and $\mathrm{P} 4)$} \\
\hline & $P_{j}$ & P1 & $\mathbf{P 2}$ & P3 & P4 & P5 & P6 & P7 & P8 \\
\hline$F_{\text {OCo }}=\begin{array}{lllllllll}0 & 0 & 0 & 0 & 0 & 0 & 0 & 1\end{array}$ & $P_{0}$ & 0 & 0 & 0 & 0 & 0 & 0 & 0 & 1 \\
\hline$F_{O C 1}=00010110$ & $P_{1}$ & 0 & 0 & 0 & 0 & 0 & 1 & 1 & 0 \\
\hline$F_{O C 2}=00101010$ & $P_{2}$ & 0 & 0 & 1 & 0 & 1 & 0 & 1 & 0 \\
\hline$F_{O C 3}=00111101$ & $P_{3}$ & 0 & 0 & 1 & 0 & 1 & 1 & 0 & 1 \\
\hline$F_{\text {OC4 }}=01001100$ & $P_{4}$ & 0 & 0 & 0 & 0 & 1 & 1 & 0 & 0 \\
\hline$F_{O C 5}=01011011$ & $P_{5}$ & 0 & 1 & 0 & 1 & 1 & 0 & 1 & 1 \\
\hline$F_{\text {OC6 }}=011100111$ & $P_{6}$ & 0 & 0 & 1 & 0 & 0 & 1 & 1 & 1 \\
\hline$F_{\text {OC7 }}=01110000$ & $P_{7}$ & 0 & 0 & 1 & 0 & 0 & 0 & 0 & 0 \\
\hline$F_{O C 8}=100001111$ & $P_{8}$ & 0 & 0 & 0 & 0 & 1 & 1 & 1 & 1 \\
\hline$F_{\text {OC9 }}=10011000$ & $P_{9}$ & 0 & 0 & 0 & 0 & 1 & 0 & 0 & 0 \\
\hline$F_{\text {oc10 }}=10100100$ & $P_{10}$ & 0 & 0 & 1 & 0 & 0 & 1 & 0 & 0 \\
\hline$F_{O C 11}=10110011$ & $P_{11}$ & 0 & 0 & 1 & 0 & 0 & 0 & 1 & 1 \\
\hline$F_{O C 12}=110000010$ & $P_{12}$ & 0 & 0 & 0 & 0 & 0 & 0 & 1 & 0 \\
\hline$F_{O C 13}=11010101$ & $P_{13}$ & 0 & 0 & 0 & 0 & 0 & 1 & 0 & 1 \\
\hline$F_{O C 14}=11101001$ & $P_{14}$ & 0 & 0 & 1 & 0 & 1 & 0 & 0 & 1 \\
\hline$F_{O C 15}=11111110$ & $P_{15}$ & 0 & 0 & 1 & 0 & 1 & 1 & 1 & 0 \\
\hline
\end{tabular}

Table 5 Generation of codes $\left(Q_{j}\right.$ and $\left.R_{j}\right)$ as per step 2, cases 2 and 3

\begin{tabular}{|c|c|}
\hline $\begin{array}{l}\text { Only } 0^{\prime} \text { 's are complemented at residue } \\
\text { positions }\left(Q_{j}\right)\end{array}$ & $\begin{array}{l}\text { Both } 1 \text { 's and } 0 \text { 's are complemented at residue } \\
\text { positions }\left(R_{j}\right)\end{array}$ \\
\hline $\mathbf{Q}_{\mathbf{0}}=11010001$ & $R_{0}=11010001$ \\
\hline$Q_{\mathbf{1}}=11010110$ & $R_{1}=11000110$ \\
\hline$Q_{2}=11111010$ & $R_{2}=11111010$ \\
\hline$Q_{\mathbf{3}}=11111101$ & $R_{3}=11101101$ \\
\hline$Q_{\mathbf{4}}=11011100$ & $R_{4}=10011100$ \\
\hline$Q_{5}=11011011$ & $R_{5}=100001011$ \\
\hline$Q_{6}=11110111$ & $R_{6}=10110111$ \\
\hline$Q_{7}=11110000$ & $R_{7}=10100000$ \\
\hline$Q_{\mathbf{8}}=11011111$ & $R_{8}=01011111$ \\
\hline$Q_{\mathbf{9}}=111011000$ & $R_{9}=010001000$ \\
\hline$Q_{10}=11110100$ & $R_{10}=01110100$ \\
\hline$Q_{11}=11110100$ & $R_{11}=011000011$ \\
\hline$Q_{\mathbf{1 2}}=11010010$ & $R_{12}=000010010$ \\
\hline$Q_{13}=11010101$ & $R_{13}=0000000101$ \\
\hline $\mathbf{Q}_{\mathbf{1 4}}=111111001$ & $R_{14}=00111001$ \\
\hline$Q_{15}=11111110$ & $R_{15}=00101110$ \\
\hline
\end{tabular}




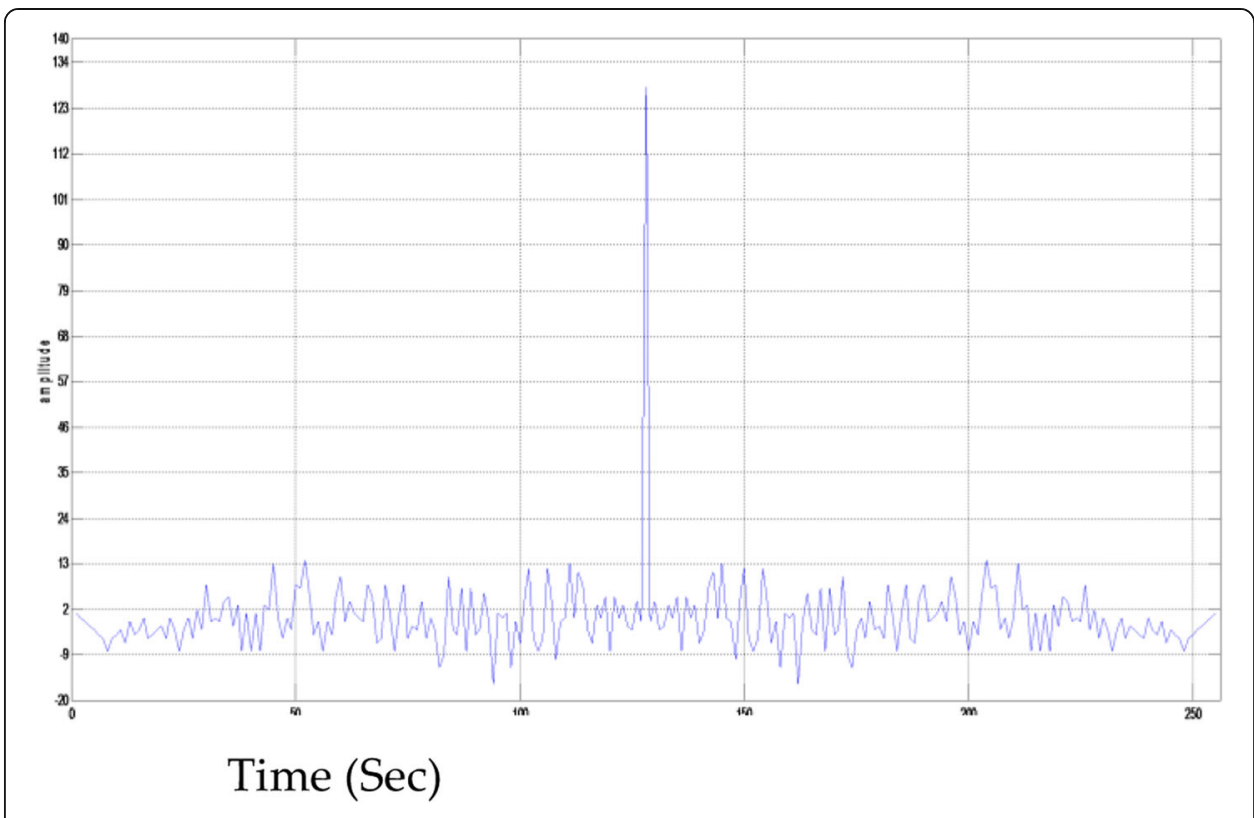

Fig. 5 Autocorrelation function of $f_{C 1}$

\subsection{Generation of 128-bit digital code}

Concatenation of codes is performed to obtain the digital code of length 128. Considering the $16 F_{O C j}$ codes, each of length of 8 -bit gives 128 -bit $(16 \times 8)$ code $\left(f_{C j}\right)$ when concatenated row wise represented as

$$
f_{c 1}=F_{O C 0} F_{O C 1} F_{O C 2} F_{O C 15}
$$

Now, the code $f_{C 1}$ is 128-bit code and is tested for the property of autocorrelation and Doppler tolerance (ambiguity) presented in Figs. 5 and 6 a and b. Figure 6 b is a 2dimensional view of Fig. $6 \mathrm{a}$ in which the clear windows can be seen.

In Fig. 5, the side noise value of the code $\left(f_{C 1}\right)$ is 13 , and the amplitude of the main lobe is 128 . The reduction ratio $\left(R_{r}\right)$ of side noise can be calculated as

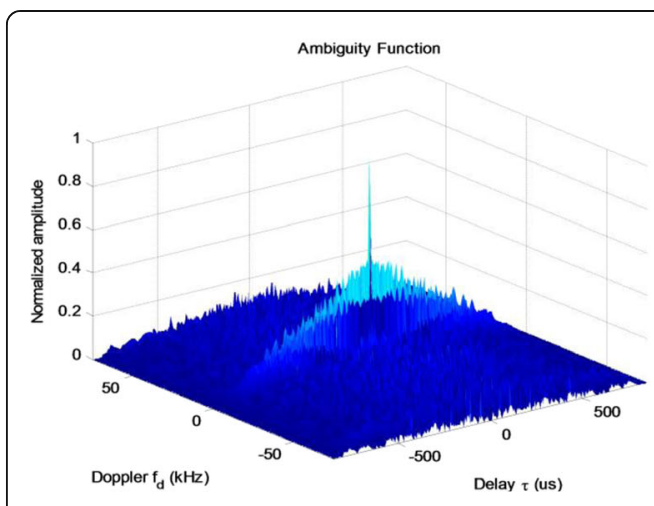

(a)

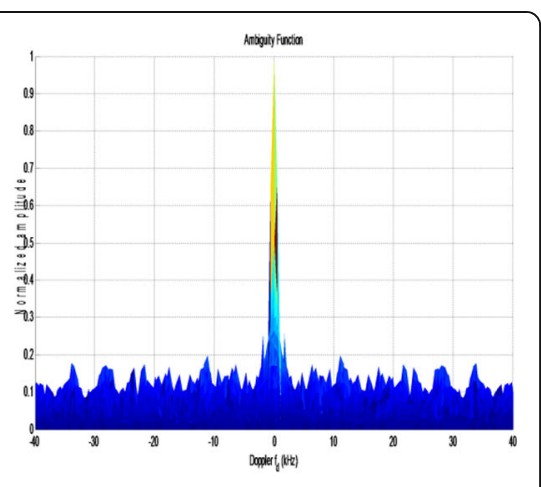

(b)

Fig. $\mathbf{6}$ a Doppler tolerance of $f_{C 1}$. $\mathbf{b}$ Amplitude $v / s$ Doppler of $f_{C 1}$ 


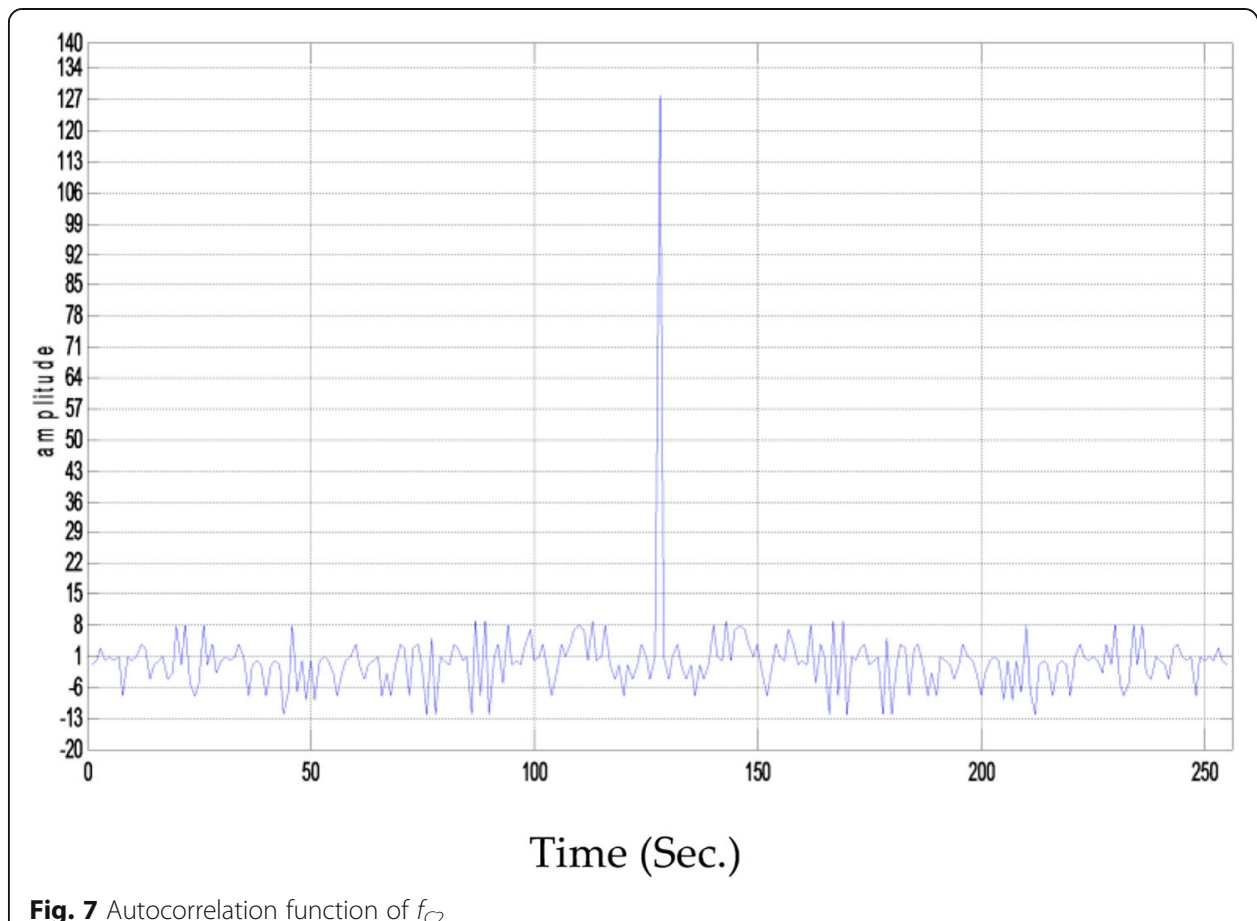

Fig. 7 Autocorrelation function of $f_{C 2}$

$$
R_{r}=20 \log _{10}\left(\frac{\text { maximum amplitude of side noise }}{\text { amplitude of main lobe }}\right)
$$

Thus, $R_{r}$ of $f_{C 1}$ given as

$$
R_{r}\left(f_{c 1}\right)=20 \log _{10}\left(\frac{13}{128}\right)=-19.87 \mathrm{~dB}
$$

From Fig. 6 b, it has been observed that the side noise is either of amplitude 0.2 or less than 0.2 , which is the standard value of noise lobe $[17,18]$. There exist almost clear

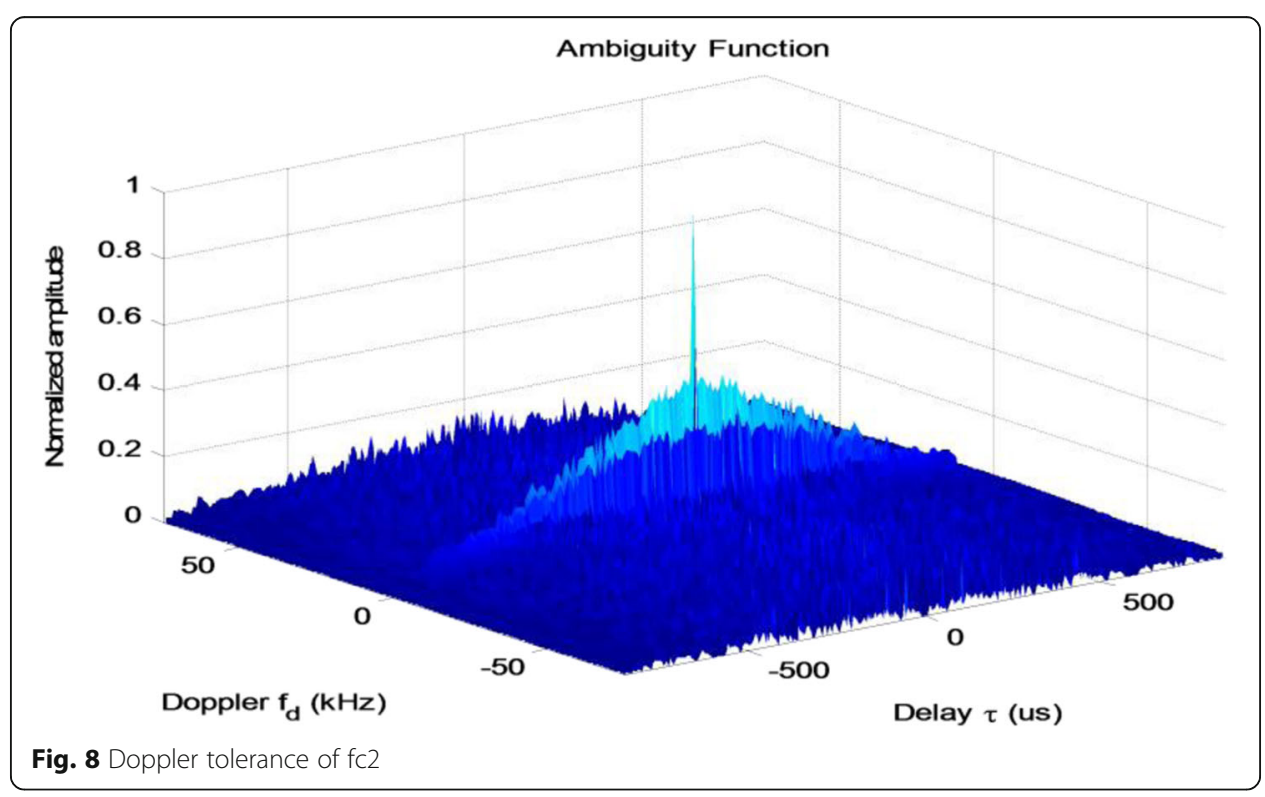


Table 6 The $R_{r}\left(f_{C 3}\right)$ and $R_{r}\left(f_{C 4}\right)$ and their clear windows

\begin{tabular}{lll}
\hline Code & $\boldsymbol{R}_{\boldsymbol{r}}$ values in $\mathrm{dB}$ & Clear windows in $\mathrm{KHz}$ \\
\hline $\boldsymbol{f}_{\mathrm{C3}}$ & -11.51 & $3-11,14-16,19-22,24-40$ \\
$\boldsymbol{f}_{\mathrm{C4}}$ & -10.10 & $2-16,19-40$ \\
\hline
\end{tabular}

windows from frequencies 2 to $40 \mathrm{kHz}$. So any moving or static object can be detected easily as it cannot mask itself.

Now consider the code $f_{C 2}$ which can be obtain by concatenation of $R_{j}$ codes row wise and can be represented as

$$
f_{c 2}=R_{0} R_{1} R_{15}
$$

The autocorrelation function of $f_{C 2}$ is presented in Fig. 7 with the side noise amplitude value as 8 and main lobe value is 128 . The $R_{r}\left(f_{C 2}\right)=-24.08 \mathrm{~dB}$. Figure 8 presents the Doppler tolerance of the code $f_{C 2}$ with the side noise of amplitude 0.2. From Fig. 8, it is observed that clear windows are from 2 to $40 \mathrm{kHz}$.

In similar fashion, the codes $f_{C 3}$ and $f_{C 4}$ are tested for autocorrelation function and Doppler tolerance where

$f_{C 3}=$ concatenation of $P_{j}$ codes (row wise) and can be given as

$$
f_{C 3}=P_{0} P_{1} P_{2} \quad P_{15}
$$

$f_{C 4}=$ concatenation of $Q_{j}$ codes (row wise) and can be given as

$$
f_{C 4}=Q_{0} Q_{1} Q_{2} \quad Q_{15}
$$

The $R_{r}\left(f_{C 3}\right)$ and $R_{r}\left(f_{C 4}\right)$ and their clear windows are presented in Table 6.

\subsection{Generation of 256-bit digital code}

These codes are obtained by concatenation of $F_{O C j}$ with $P_{j}$ or $Q_{j}$ or $R_{j}$ such that

$$
\begin{aligned}
& f_{C 5}=F_{O C 0} P_{0} F_{O C 1} \quad F_{O C 15} P_{15} \\
& f_{C 6}=F_{O C 0} Q_{0} F_{O C 1} Q_{1} \quad F_{O C 15} Q_{15}
\end{aligned}
$$

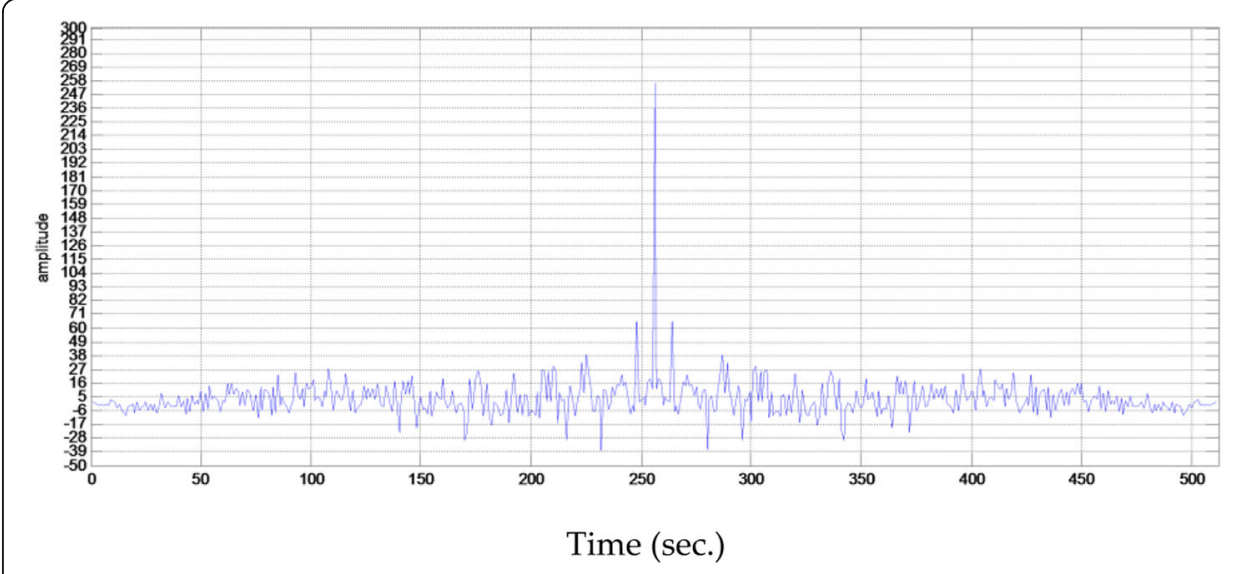

Fig. 9 Autocorrelation function of $f_{C 5}$ 


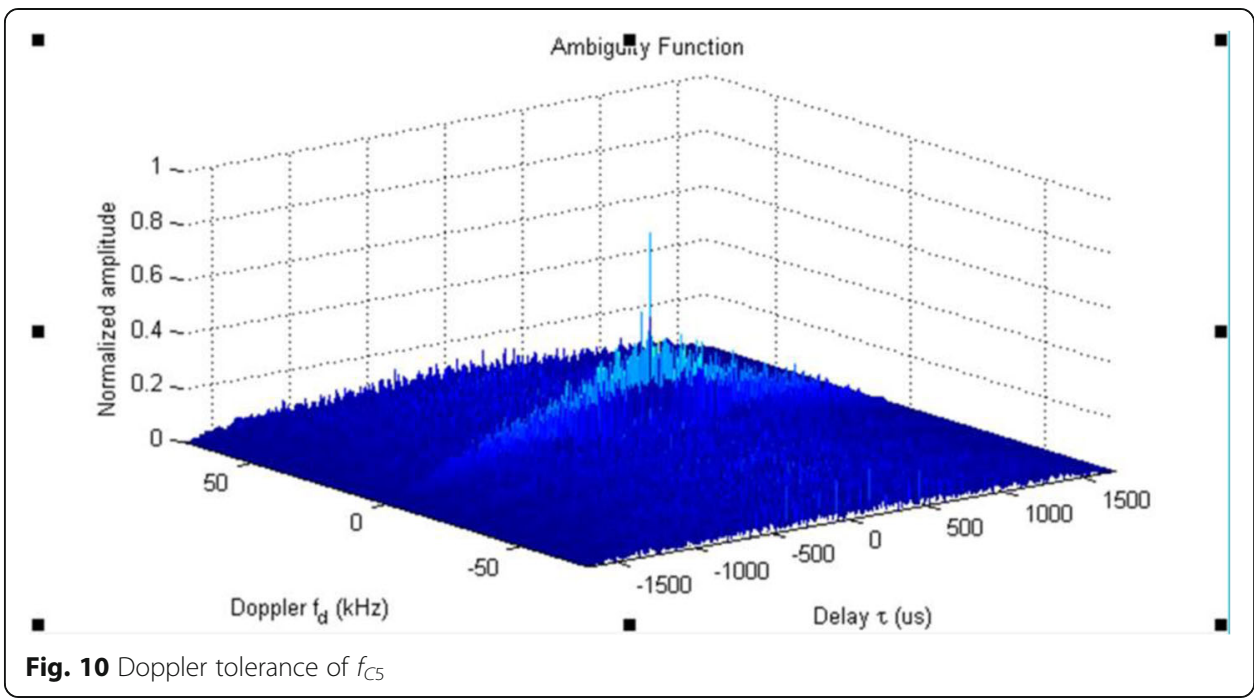

$$
f_{C 7}=F_{O C 0} R_{0} F_{O C 1} R_{1} \quad F_{O C 15} R_{15}
$$

The autocorrelation and Doppler tolerance of these codes are shown in Figs. 9, 10, $11,12,13$, and 14 .

Table 7 presents the $R_{r}\left(f_{C 5}\right), R_{r}\left(f_{C 6}\right), R_{r}\left(f_{C 7}\right)$, and their clear windows.

From the above results, it is evident that code $f_{C 2}$ and $f_{C 7}$ of lengths 128 and 256 respectively gives better results when compared to the other codes obtained.

\section{Results and discussion}

Multiple radar systems use many antennas for communication and target detection. Interference between any two radar signals should be minimized to detect the static as

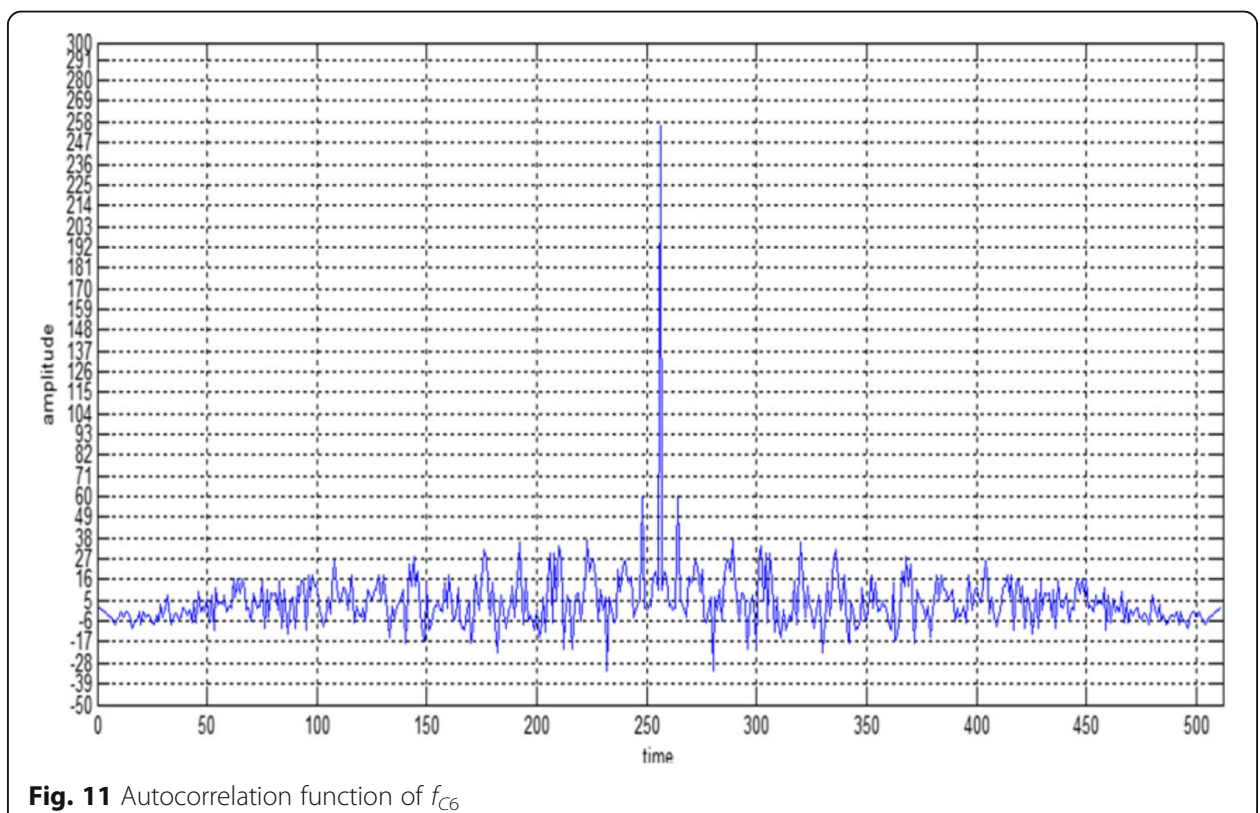

Fig. 11 Autocorrelation function of $f_{C 6}$ 


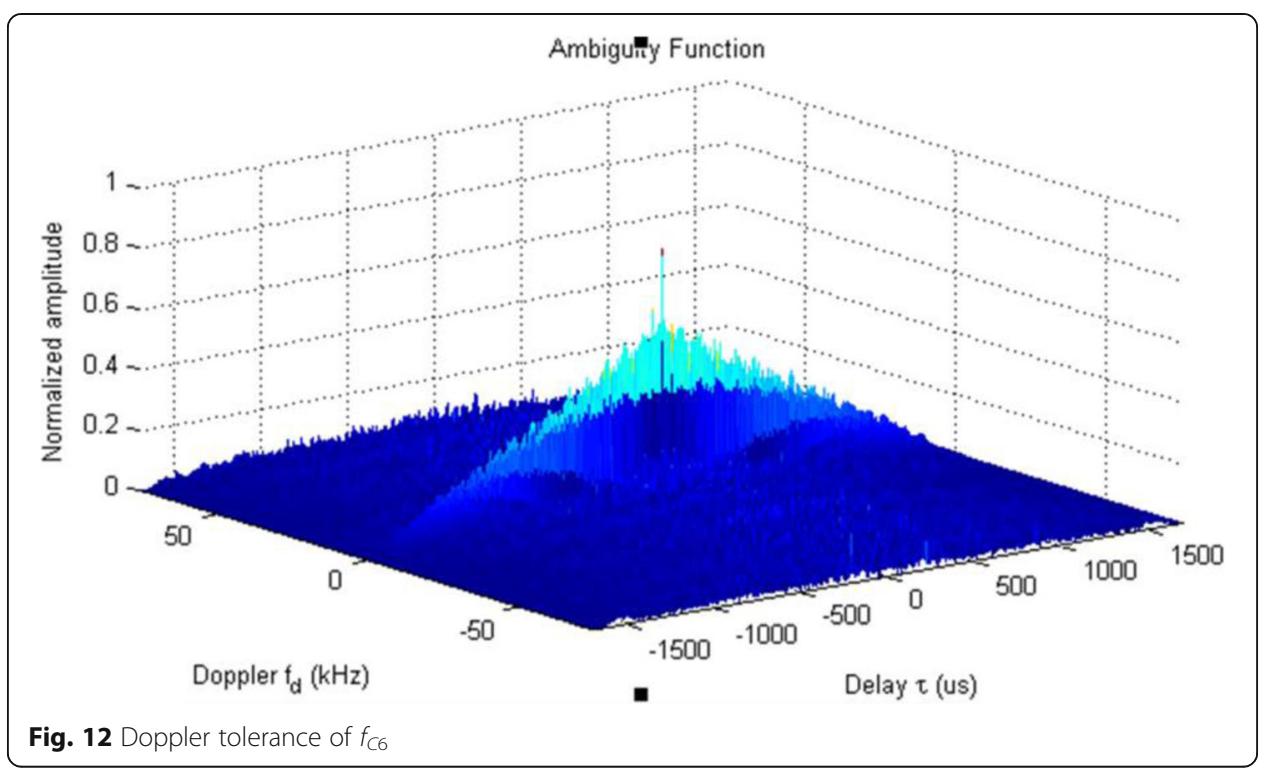

well as moving target precisely; therefore, the sequences used must have better autocorrelation and Doppler tolerance.

Simulation results (shown in Table 8) depict that the designed binary sequences show improvised autocorrelation properties when compared to the existing techniques such as Barker codes, Golay codes, PTM, and over-sampled PTM (discussed in Section 3). The Kasami and Gold codes in [22, 23] are compared with the proposed binary codes. The proposed code gives better autocorrelation response when compared with Kasami and Gold codes which are commonly used to reduce side lobes in radar target detection process and are also applicable to static objects only. For moving object detection, the Doppler tolerance of the proposed codes is compared with [17, 18]. The proposed approach gives large clear windows when compared with the existing methods. The

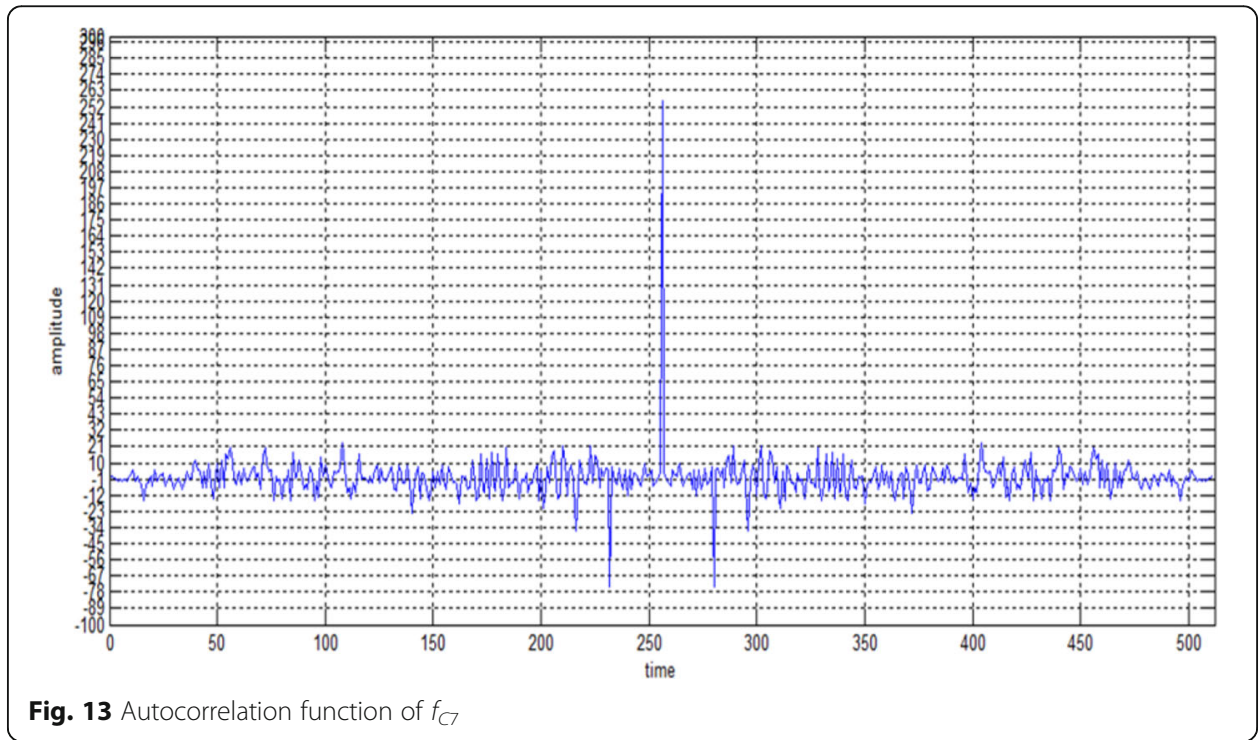




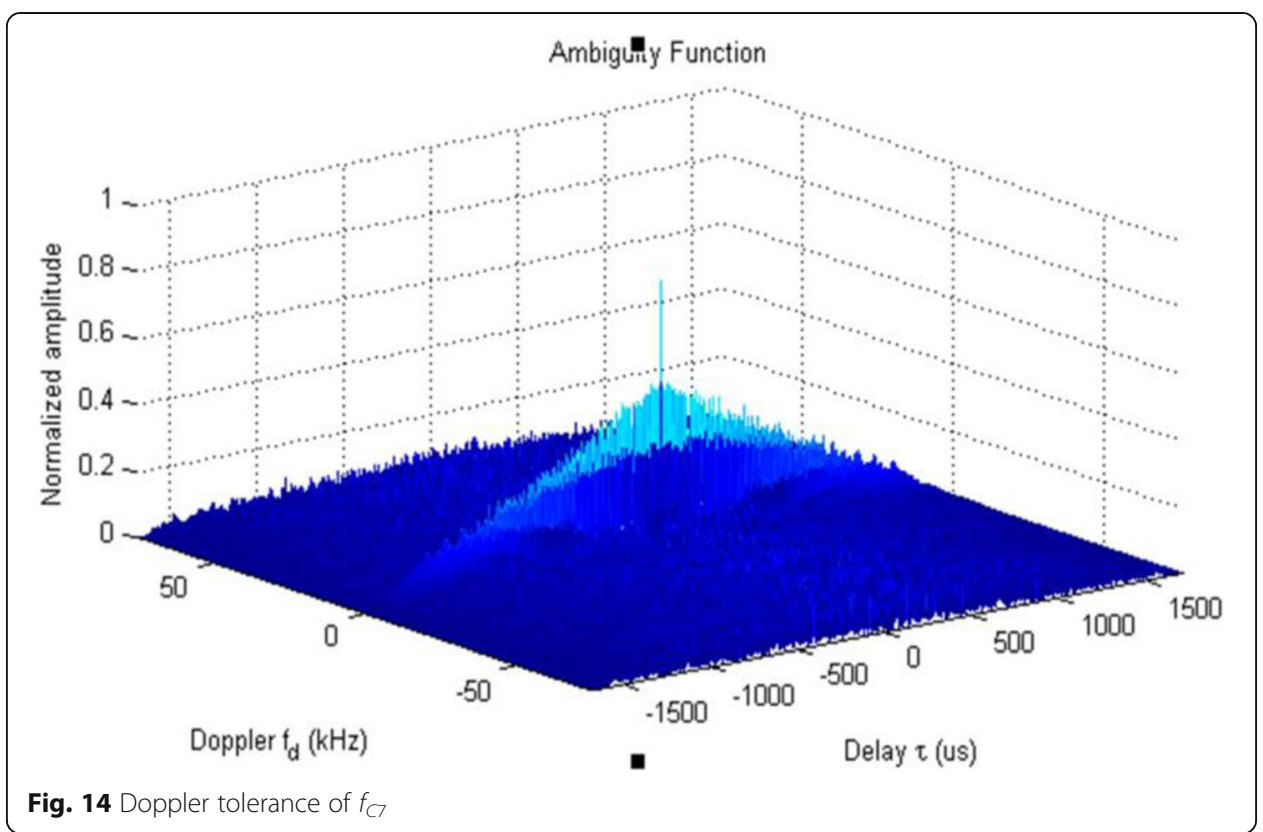

length of the codes is not limited; one can design the sequence up-to-the desired length by using mathematical operations. The designed sequences have optimal side noise, and different clear windows have been obtained with respect to different Doppler. These windows can be used to detect the moving targets with respect to the desired Doppler. In the detection process, a matched filter is used, and the step of the range gate can be mitigated which reduces the hardware. Hence, using four A-scope or PPI (plan position indicator) units (receiver devises) for different sequences (i.e., of 128and 256-bit length) will cover the entire range of Doppler shift as a result of which no target in the multi-target environment is missed. Hence, the designed sequences can be used for multiple radar systems to communicate and detect the targets (both static and moving) with high resolution, improvised range, precise target detection, and minimum interference.

\section{Conclusion}

The presented codes are easy to implement and useful to detect stationary and moving objects together with enhanced autocorrelation characteristics in the presence of Doppler. The proposed series of codes have a distinctive benefit against the state-of-the-art (i.e., PTM, Barker, over-sampled PTM, Golay, Gold codes and Kasami) that every code follows orthogonality principle to decrease the numerical complication. These codes can be obtained from linear block code by amending arithmetic and information

Table $7 R_{r}\left(f_{C 5}\right), R_{r}\left(f_{C 6}\right), R_{r}\left(f_{C 7}\right)$, and their clear windows

\begin{tabular}{lll}
\hline Code & $\boldsymbol{R}_{\boldsymbol{r}}$ values in $\mathrm{dB}$ & Clear windows in $\mathrm{KHz}$ \\
\hline $\boldsymbol{f}_{\mathrm{C5}}$ & -16.57 & $1-40$ \\
$\boldsymbol{f}_{\mathrm{C6}}$ & -16.57 & $1-40$ \\
$\boldsymbol{f}_{C 7}$ & -21.72 & $1-40$ \\
\hline
\end{tabular}


Table $8 R_{r}$ values and clear windows of the codes obtained

\begin{tabular}{lll}
\hline Code & $\boldsymbol{R}_{\boldsymbol{r}}$ values in $\mathbf{~ B B}$ & Clear windows in $\mathbf{k H z}$ \\
\hline $\boldsymbol{f}_{\boldsymbol{C 1}}$ & -19.87 & $2-40$ \\
$\boldsymbol{f}_{\mathrm{C2}}$ & -24.08 & $2-40$ \\
$\boldsymbol{f}_{\boldsymbol{C 3}}$ & -11.51 & $3-11,14-16,19-22,24-40$ \\
$\boldsymbol{f}_{C 4}$ & -10.10 & $2-16,19-40$ \\
$\boldsymbol{f}_{C 5}$ & -16.57 & $1-40$ \\
$\boldsymbol{f}_{C 6}$ & -16.57 & $1-40$ \\
$\boldsymbol{f}_{C 7}$ & -21.72 & $1-40$ \\
\hline
\end{tabular}

theory. These codes reduce one step of target recognition (i.e., range gates) which reduces the delay and price of the equipment. The designed codes are well suitable to sense multiple moving and fast objects on top of MAC-3, i.e., 5th generation combatant vehicles. Multiple clear windows are created by using the designed codes with noise amplitudes reduced to $0.2 \mathrm{~dB}$ (which is the standard threshold limit).

\section{Acknowledgements}

Not applicable.

\section{About the Authors}

Majid Alotaibi received his Ph.D. from The University of Queensland, Brisbane, Australia, in 2011. Currently, he is an associate professor with the Department of Computer Engineering, Umm Al-Qura University, Makkah, Saudi Arabia. He is a Co-founder of the SMarT Lab. His current research interests include mobile computing, Networks: mobile and sensor networks, and computer networks, Internet of Things (IoT): wireless technologies, IoT in Healthcare, Smart Cities, and RFID, Communications: antennas and propagation, protocols, and radar.

\section{Declaration}

The research work is implemented, and the experiment is carried out.

\section{Author's contributions}

The digital codes using linear block coding technique has been designed and tested to improve the signal-to-noise ratio and create multiple windows with respect to different Doppler to get the clear information about static and multiple targets. The author read and approved the final manuscript.

\section{Funding}

Not applicable.

\section{Availability of data and materials}

Not applicable.

\section{Competing interests}

The author declared that there is no conflict of interest.

Received: 13 September 2020 Accepted: 29 December 2020

Published online: 03 February 2021

\section{References}

1. P. Addabbo, A. Aubry, A. De Maio, L. Pallotta, S.L. Ullo, HRR profile estimation using SLIM. IET Radar, Sonar Navigation 13(4), 512-521 (2019)

2. Aubry, A., Carotenuto, V., De Maio, A., et al.: 'High range resolution profile estimation via a cognitive stepped frequency technique'. IEEE Trans. Aerosp. Electron. Syst 55(1), 444-458 (2018). https://doi.org/10.1109/TAES.2018.2880024

3. N. Levanon, Mitigating range ambiguity in high PRF radar using inter-pulse binary coding. IEEE Transact. Aerosp. Electron. Syst 45(2), 687-697 (2009). https://doi.org/10.1109/TAES.2009.5089550

4. S. Shi, Z. Zhao, J. Liu, Comparison of radar waveforms combining pseudo-random binary phase coding and chirp modulation for an high-frequency monostatic radar. IET Radar, Sonar Navigation 10(5), 935-944 (2016). https://doi.org/ 10.1049/iet-rsn.2014.0507

5. R. Tian, G. Zhang, R. Zhou, W. Dong, Detection of polyphase codes radar signals in low SNR. Math. Probl. Eng. 2016, 1-6 (2016). https://doi.org/10.1155/2016/1382960

6. F.F. Kretschmer, B.L. Lewis, Doppler properties of polyphase coded pulse-compression waveforms. IEEE Trans. Aerosp. Electron. Syst. AES-19(4), 521-531 (1983)

7. R. Sivaswami, Self-clutter cancellation and ambiguity properties of sub complementary sequences. IEEE Trans. Aerosp. Electron. Syst. AES-18(2), 163-181 (1982) 
8. J.-H. Guey, M.R. Bell, Diversity waveform sets for delay-Doppler imaging. IEEE Trans. Inform. Theory 44(4), 1504-1522 (1998)

9. G.E. Coxson, W. Haloupek, Construction of complementary code matrices for waveform design. IEEE Transactions on Aerospace and Electronic Systems 49(3), 1806-1816 (2013). https://doi.org/10.1109/taes.2013.6558021

10. C.-F. Chang, M.R. Bell, Frequency-coded waveforms for enhanced delay-Doppler resolution. IEEE Transact. Information Theory 49(11), 2960-2971 (2003). https://doi.org/10.1109/tit.2003.818408

11. H. Deng, Poly-phase code design for orthogonal netted radar systems. IEEE Transactions on Signal Processing 52(11), 3126-3135 (2004). https://doi.org/10.1109/tsp.2004.836530

12. A. Pezeshki, R. Calderbank, L.L. Scharf, Sidelobe suppression in a desired range/Doppler interval (IEEE Radar conference 2009 at Pasadena, CA, 2009), pp. 1-5

13. H. Deng, Synthesis of binary sequences with good autocorrelation and cross-correlation properties by simulated annealing. IEEE Trans. Aerosp. Electron. Syst. 32, 98-107 (1996)

14. Gladkova, I., \& Chebanov, D.. Suppression of grating lobes in stepped-frequency train. IEEE International Radar Conference, 2005, pp. 371-376

15. N. Levanon, E. Mozeson, Nullifying ACF grating lobes in stepped-frequency train of LFM pulses. IEEE Trans. Aerosp. Electron. Syst. 39(2), 694-703 (2003)

16. J.D. Jenshak, J.M. Stils, "A fast method for designing optimal transmit codes for radar" IEEE Radar Conference (2008), pp. 1038-1042 26-30 May 2008

17. M. Alotaibi, in International Conference on Communications and Cyber Physical Engineering, Lecture Notes in Electrical Engineering. Improved target detection in Doppler tolerant radar using a modified hex coding technique (Springer, Singapore, 2018), pp. 63-72

18. M. Aleem, R.P. Singh, S.J. Ahmad, in Innovations in Electronics and communication engineering, Lecturer Notes in Networks and Systems Vol 33. Enhance multiple moving target detection in Doppler tolerant radar using IRAESC technique (Springer, Singapore, 2019), pp. 417-426

19. C.G. Raghavendra, N. Harsha, S. Mohan Kumar, H.S. Prashantha, Joint reduction of PMEPR and sidelobe in multicarrier radar signals using ZC and SC method. WSEAS Trans. Commun. 19, 9-17 (2020)

20. N. AdithyaValli, D. Elizabath Rani, C. Kavitha, Convolution windows for side lobe reduction. Int. J. Innov. Technol. Exploring Eng. 8(10), 3526-3529 (2019)

21. M.J.E. Golay, Complementary series (1961). IRE Trans. Inform. Theory 7(2), 82-87 (1961)

22. A. Khatter, P. Goyal, Design and analyze the various m-sequences codes in MATLAB. Int. J. Emerg. Technol. Adv. Eng., ISSN 2250-2459 2(11) (2012)

23. I.G.A.G.K. NyomanPramaita, D.H. Diafari, D.N.K.P. Negara, A. Dharma, New orthogonal small set Kasami code sequence. Majalah IImiah Teknologi Elektro 14(1) (2015). https://doi.org/10.24843/mite.2015.v14i01p10

\section{Publisher's Note}

Springer Nature remains neutral with regard to jurisdictional claims in published maps and institutional affiliations.

\section{Submit your manuscript to a SpringerOpen ${ }^{\circ}$ journal and benefit from:}

- Convenient online submission

- Rigorous peer review

- Open access: articles freely available online

- High visibility within the field

- Retaining the copyright to your article

Submit your next manuscript at $\boldsymbol{s p r i n g e r o p e n . c o m ~}$ 